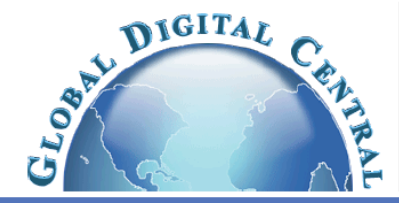

Frontiers in Heat and Mass Transfer

Available at www.ThermalFluidsCentral.org

\title{
THERMO-HYDRAULICS OF TUBE BANKS WITH POROUS INTERCONNECTORS USING WATER AS COOLING FLUID
}

\author{
P. V. Ramana, Arunn Narasimhan*, Dhiman Chatterjee \\ Department of Mechanical Engineering, Indian Institute of Technology Madras, Chennai - 600036, India
}

\begin{abstract}
The present experimental study investigates the effect of tube-to-tube porous interconnectors on the pressure drop and heat transfer (Nu) of tube banks. A copper wire mesh porous medium connects successive tubes of the in-line and staggered arrangement of six rows of tubes. The tubes are subjected to constant and uniform heat flux and cooled by forced convection using water as a cooling fluid in the laminar flow range $\left(100<\mathrm{Re}_{D u c t}\right.$ $<625)$. The inline configuration with the tube-to-tube porous medium inter-connectors provides marginal enhancement of heat transfer and $12 \%$ reduction in the pressure drop penalty respectively, compared to tube banks without porous medium inter-connectors. Using numerical simulations the marginal heat transfer increase is attributed to contact resistance due to poor thermal contact between the tubes and the porous medium. Despite this, the staggered tube bank configuration exhibit 50\% heat transfer enhancement, with the tube-to-tube porous medium inter-connectors. However, the pressure drop penalty is three times more than that for tube banks without porous medium interconnectors.
\end{abstract}

Keywords: Forced convection, Tube bank, Heat transfer enhancement, Porous medium, Interconnectors, Heat exchangers.

\section{INTRODUCTION}

Heat exchangers are ubiquitous in engineering and industrial applications ranging from household devices to electronics and power plant cooling. A promising approach of performance enhancement is to use porous medium in the heat exchanger Lage and Narasimhan (2000). The large surface area, good permeability and high thermal conductivity of suitable porous media contribute to the enhancement of heat transfer. The excellent mixing of the fluid due to its tortuous flow path within the porous medium increases the fluid retention time and thus improves heat transfer. The increase in pressure drop, however, is strongly dependent on the configuration of the porous medium.

The investigations by Lauriat and Ghafir (2000) using porous medium to enhance the rate of heat and mass transfer in energy systems show that the Nusselt number values are approximately 50\% higher than the values predicted for laminar flows in a channel without porous materials. This is due to the higher thermal conductivity of the porous matrix compared to the clear fluid. The experimental and numerical results reported by Bogdan and Mohamad (2004b,a) have shown an improvement in heat transfer along with a reasonable increment in pressure drop penalty using porous inserts filled in a pipe. Comparison of the results obtained with pipes fully filled and partially-filled with porous inserts showed that the partially-filled case provides reduced pressure drop with comparable heat transfer. A similar experimental study done by Huang et al. (2010) reports of porous medium inserts at the core of the tube for heat transfer enhancement. The heat transfer rate of the tube with porous inserts whose diameters approach the diameter of the tube is about 1.6 to 5.5 times larger than the smooth tube cases in laminar, transitional and turbulent ranges of Reynolds numbers.
Raju and Narasimhan (2007) have investigated forced convection of inline tube banks with porous inserts under laminar flow. They have reported uniform heat transfer enhancement for all configurations and less pressure drop for some configurations than the configurations without porous inserts. Straatman et al. (2006) studied thin layers of low porosity carbon foam (porosity varying between 0.67 and 0.84 ) brazed on top of a heater plate surface as a 'roughness' element to enhance heat transfer. The results propose the thickness of the foam to be selected based upon the depth of penetration of air, which for parallel flow applications was deduced to be approximately $3 \mathrm{~mm}$. The experiments provide an insight into use of thin layers of foam material on tube surfaces to act as a heat transfer enhancer without much increase in pressure drop. A related, experimental study by TŠJoen et al. (2010) uses a high porosity aluminium foam (porosity varying between 0.91 and 0.95 ) to evaluate the thermo-hydraulic performance of single row heat exchangers consisting of aluminium tubes covered with metal foam. Increasing the foam height reduced the exterior convective resistance but incurred increased pressure drop. They also reported the effect of the bonding contact resistance of the porous medium on the heat exchanger performance.

In another experimental work by Jamin and Mohamad (2007), aluminium fins and carbon foam porous medium were used as attachments in vertical pipes. The aluminium fins experienced better heat transfer than the carbon foam porous medium. Yu et al. (2006) developed engineering models based on unit-cube geometry and the results obtained compared well with the measured results from carbon foam finned tube air water radiator. Up to $15 \%$ improvement in thermal performance over conventional aluminum radiators is reported using

*Corresponding author. Email: arunn@iitm.ac.in 
carbon finned tubes.

In numerical investigation of heat transfer performance of a staggered tube bundle with various low conductivity wooden porous media inserts at $100<\operatorname{Re}<300$ and for $\operatorname{Pr}=0.7$, Layeghi (2008) showed a heat transfer enhancement of more than $50 \%$ in some cases. Forced convection heat transfer from an elliptical pin fin heat sink with and without metal foam inserts was studied using numerical simulations by Seyf and Layeghi (2010). The Nusselt number was shown to increase by more than $400 \%$ in some cases with a decrease in porosity and an increase in Reynolds number. However, the pressure drop increases with decreasing permeability and increasing Reynolds number.

Based on the literature survey it can be summarised that a proper selection of metal foam inserts is crucial for enhancement of heat transfer characteristics. The objectives of this work are to perform an experimental investigation on the use of tube-to-tube porous interconnectors to reduce pressure drop in the inline tube bank arrangement as suggested in Raju and Narasimhan (2007) and to study the heat transfer effects for the staggered tube bank arrangement.

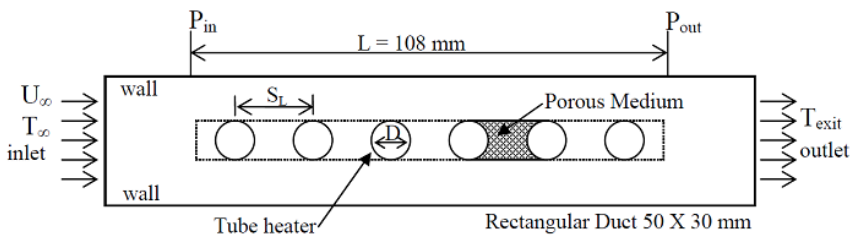

(a)
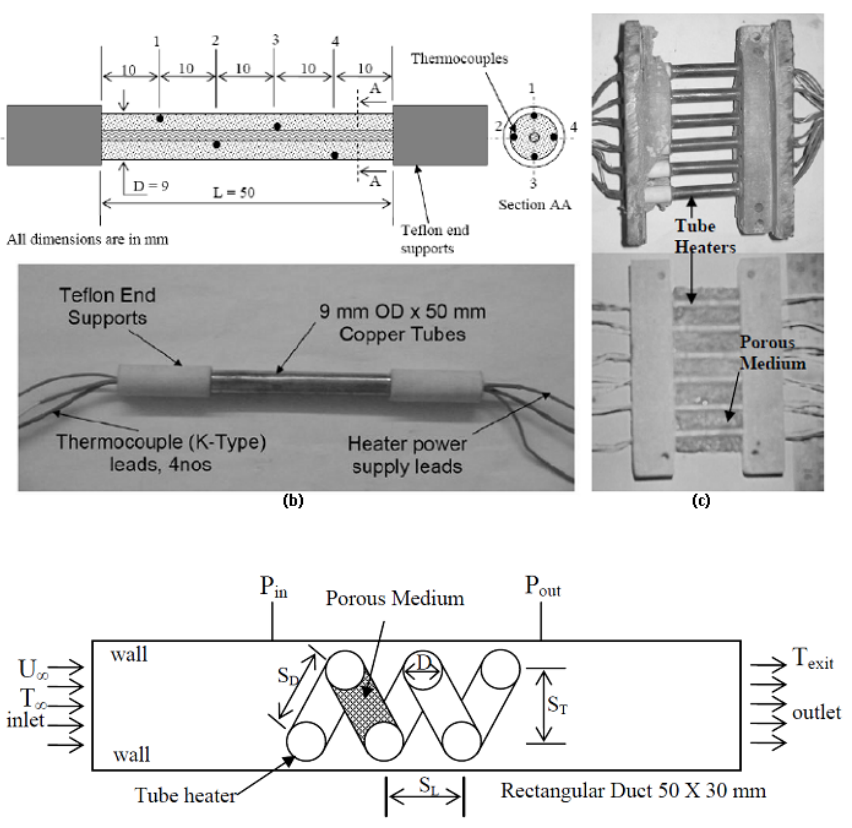

(d)

Fig. 1 Schematic of test domain considered for study (a) inline arrangement (b) thermocouple arrangement on tube heater surface (c) assembled tube heaters with and without tube-to-tube porous medium inter-connectors (d) staggered arrangement

\section{EXPERIMENTAL SETUP AND INSTRUMENTATION}

Figure 1(a) shows the schematic of the inline configuration considered for the forced convection heat transfer experiments. Here six tubes, each $9 \mathrm{~mm}$ in diameter and $50 \mathrm{~mm}$ in length were placed inline along the flow direction having square pitch of $X_{T}=X_{L}=2.0$ and the porous medium of thickness equal to the tube diameter $(\mathrm{t}=\mathrm{D})$ was used to connect successive tubes to create the inline configuration with porous medium interconnectors. The hollow tubes were fitted with heating coil to simulate the hot fluid flow in a heat exchanger, generating constant and uniform heat flux from the tube surface. Four T-type thermocouples were placed on each of these tube heaters to monitor and record surface temperature of the tube surface. The thermocouple arrangement and heater construction are shown in Fig. 1(b). Before placing the heaters in the test section each heater was tested under a steady state conditions and the surface temperatures were recorded. The maximum surface temperature difference was verified to be less than $2{ }^{\circ} \mathrm{C}$ to ensure uniformity of surface heat flux. The electrical power input to the heater was calculated from the measured current and voltage across them using digital multimeter.

The tube heaters were placed in an adiabatic $150 \mathrm{~mm} \times 50 \mathrm{~mm} \times$ $30 \mathrm{~mm}$ rectangular test section. The tubes exchanged heat with cross-flowing cooling water. The flow was laminar as the Reynolds number based on the channel hydraulic diameter was in the range of $100<R e_{\text {Duct }}<625$. All the four walls of the housing were made of an insulating material called Cynthiana $(\mathrm{k}=0.04 \mathrm{~W} / \mathrm{m}-\mathrm{K})$ to ensure adiabatic conditions.

The schematic of the experimental test rig is presented in Fig. 2. It comprises a centrifugal pump, constant head water tank, water sump, strainer, test section, Agilent-make data acquisition system, measuring tank, differential pressure transmitter, thermocouples, a regulated DC power supply (TDK-Lamda, Model: LD15010) for electrical power input and digital multimeters. Distilled water was used as cooling fluid. A centrifugal pump (JYOTI make, Model No: JP 140, Capacity: 0 to 20 $\mathrm{m}$ head, 0 to 10 LPM discharge) was used to transport the water from the sump to the overhead water tank to maintain constant level. The sediments and rust particles were filtered during recirculation using fine filter at the suction line of the pump. The overflow line provided with the overhead water tank was used to maintain constant level of water in the tank, thus ensuring constant pressure water supply throughout the experiments.

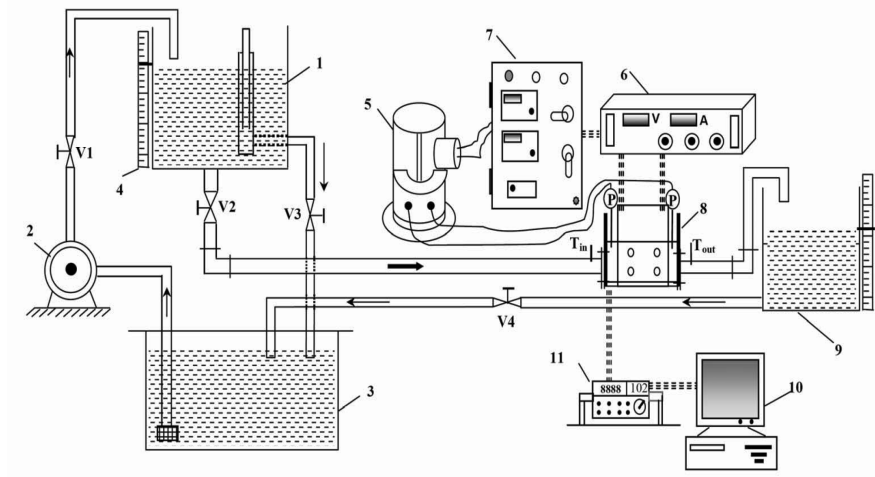

1. constant head water tank, 2 . self-priming pump $(0.25 \mathrm{~h} \mathrm{p}), 3$. sump, 4 . water level indicator, 5 . differential pressure transducer, 6. DC power supply, 7. control panel with digital multimeters, 8. test section, 9. measuring can, 10. data acquisition system, 11. data recording system.

Fig. 2 Schematic diagram of the experimental setup

Figure 1(c) shows the inline tube arrangement with and without porous medium inter-connectors fitted in the insulated side walls of the test section. The entire heat transfer test section was wrapped in ceramic wool to minimize heat loss. The temperature of the inlet water was measured by two T-type thermocouples fixed in crosswise direction at the inlet of duct. Four thermocouples were located at the exit of the test section to measure the outlet temperature of the fluid. The water flow rate was measured using a stop watch and a measuring tank i.e. by 
measuring the water collected for specified time duration. The flow rate and input power were fixed for each test. Figure 1(d) depicts the staggered tube bank arrangement considered for thermo-hydraulic performance study with porous medium interconnectors. The detailed instrumentation is discussed in Ramana et al.Ramana et al. (2010).

\section{EXPERIMENTAL PROCEDURE}

Hydraulic and forced convection experiments were conducted on a row of six cylinders first kept in inline and then in staggered arrangement inside the test section without the porous medium inter-connectors. Longitudinal steady state pressure drop across the test section was measured for several flow rates in the tube diameter based Reynolds number range of $0<R e_{D}<150$. Corresponding heat transfer experiments were also conducted to determine the steady state overall Nusselt number $(\mathrm{Nu})$. The $R e_{D}$ and $\mathrm{Nu}$ are defined as

$$
\begin{gathered}
\operatorname{Re}_{D}=\frac{\rho U D}{\mu} \\
N u=\frac{q D}{A N\left[\bar{T}_{w}-\bar{T}_{\text {avg_exit }}\right] k_{f}}
\end{gathered}
$$

where all the terminology involved are explained in the nomenclature.

By regulating the voltage and current from the DC power source, a constant and uniform $300 \mathrm{~W}$ energy was supplied to all six tube heaters. Steady state was assumed to be reached when the deviations of the tube wall temperatures as well as the inlet and outlet temperatures were within $\pm 0.1^{\circ} \mathrm{C}$ for a span of ten minutes. The system typically took three to four hours to reach this steady state. Once steady state was reached, all the temperatures, pressures and water flow rate were recorded. The mean of the temperatures of the six tube walls (i e. 24 on all tubes) were used to determine $\bar{T}_{W}$ in Eq. (2). The average exit temperature $\bar{T}_{a v g_{e} x i t}$ of the fluid was measured using four T-type thermocouples fitted at the exit of the test section. Using these data the average exit temperature $\bar{T}_{a v g_{e} x i t}$ was calculated.

The uncertainties in the primary measured quantities were obtained from the calibration of the instruments or the uncertainty prescribed by the manufacturer. The uncertainties in the measured physical quantities were $\pm 0.02 \mathrm{~mm}$ for linear dimensions, $\pm 5 \mathrm{ml}$ for flow measurement, $\pm 0.1{ }^{\circ} \mathrm{C}$ for temperature and $\pm 0.25 \%$ for pressure measurement. The uncertainty, $w_{R}$, in the dependent variable $\mathrm{R}$, was estimated by following the procedure Holman (2001) given below.

$$
w_{R}= \pm\left\{\sum_{i=1}^{n}\left[\left(\frac{\partial R}{\partial x_{i}}\right)^{2} w_{x_{i}}^{2}\right]\right\}^{1 / 2}
$$

where ' $\mathrm{x}$ ' is the independent variable and $w_{x}$ is the uncertainty associated with ' $x$ ', Using this procedure, the uncertainty in the average Nusselt number, pressure drop and Reynolds number was calculated as $\pm 5.2 \%$, $\pm 3.6 \%$ and $\pm 2.8 \%$ respectively.

The experimental setup was verified for both hydraulic and heat transfer measurements for inline arrangement of tubes without porous medium interconnectors by comparing the obtained pressure-drop and Nusselt number data with the established tube bank correlations Zukauskas (1987).

Copper wire mesh porous media used as interconnectors in this study were tested to determine the hydraulic properties such as porosity, permeability and form coefficient. The porous medium was filled in a separate rectangular duct and the longitudinal pressure drop for several flow rates in the identical range of $R e_{D u c t}$ were measured. The data was curve-fit using the global Hazen-Dupuit-Darcy (HDD) porous medium model

$$
\frac{\Delta P}{L}=\frac{\mu}{K} U+\rho C U^{2}
$$

The permeability $\mathrm{K}$ and the form coefficient $\mathrm{C}$ of the porous medium were determined from the curve-fit coefficients as $\mathrm{K}=4.183 \times 10^{-7} \mathrm{~m}^{2}$ and $\mathrm{C}=43.5836 \mathrm{~m}^{-1}$ with uncertainties $\mathrm{U}_{K} / \mathrm{K}= \pm 6.9 \%, \mathrm{U}_{C} / \mathrm{C}= \pm$ $3.7 \%$. The volumetric porosity of the mesh was determined as $\phi=0.58$ using standard immersion technique.

\section{RESULTS AND DISCUSSION}

The objective of the present study as stated earlier, is to understand the effects of tube-to-tube porous medium interconnectors on thermo-hydraulic behaviour of confined inline and staggered tube banks. Accordingly, these effects are discussed in this section.

Figure 3 shows the comparison of longitudinal pressure-drop for inline tube arrangement with and without tube-to-tube porous medium inter-connectors. As expected for the range of $\operatorname{Re}_{D}$ studied here, the pressure-drop increase with increasing $\operatorname{Re}_{D}$ is quadratic. Interestingly, it can be observed that the inline configuration with porous medium interconnectors experiences lesser pressure-drop when compared with plain inline tube configuration. This reduction can be attributed to the absence of the pressure drop penalty originally caused by the recirculation and vortices behind individual tubes in the inline configuration without the porous medium. A similar observation was made by Raju and Narasimhan (2007) in their numerical study of inline tube bank with porous interconnectors. In the present experimental study a maximum of 12 percent pressure drop reduction was observed for the range of flow considered.

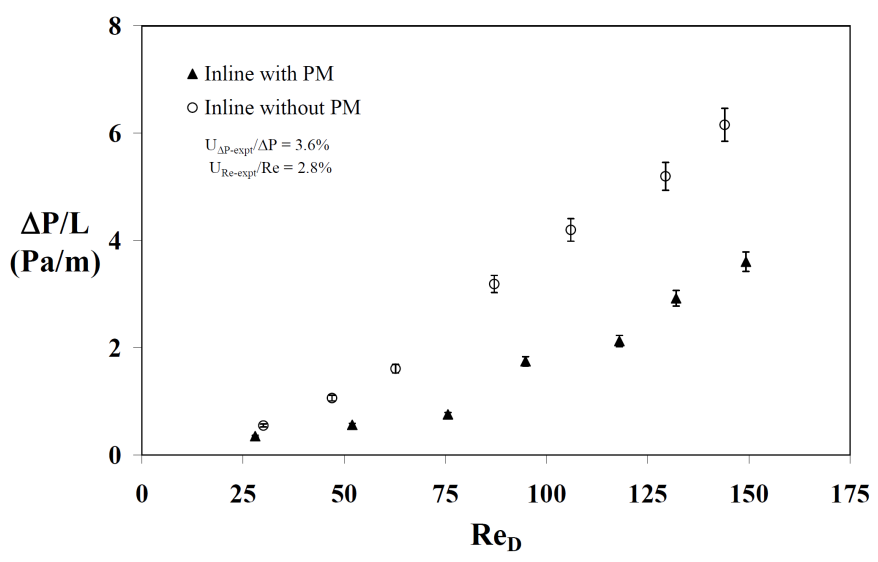

Fig. 3 Longitudinal pressure drop for different Reynolds numbers for inline arrangement

Figure 4 shows the comparative heat transfer characteristics of the inline configuration with and without tube-to-tube porous medium interconnectors. The experimental results are plotted in Fig. 4 along with the empirically predicted results using the equation given below by Zukauskas Zukauskas (1987) is general tube bank correlation with error band of $\pm 20 \%$. The two dotted lines indicate the upper and lower bound of the equation Eq. (5).

$$
N u_{D}=C_{1} C_{2} \operatorname{Re}_{D, \max }^{n} \operatorname{Pr}^{m}\left(\operatorname{Pr} / \operatorname{Pr}_{s}\right)^{0.25}
$$

where for the present inline configuration the value of constants are $\mathrm{C}_{1}=$ $0.945, \mathrm{C}_{2}=0.9, \mathrm{n}=0.4$ and $\mathrm{m}=0.36$ for the flow range $0<\mathrm{Re}_{D, \max }<$ 100 and $\mathrm{C}_{1}=0.945, \mathrm{C}_{2}=0.52, \mathrm{n}=0.5$ and $\mathrm{m}=0.36$ for $100<\mathrm{Re}_{D, \max }$ $<1000$ flow range respectively. The $\operatorname{Re}_{D, \text { max }}$ in the equation Eq. (5) is defined as

$$
R e_{D, \max }=\frac{\rho U_{m} D}{\mu}
$$




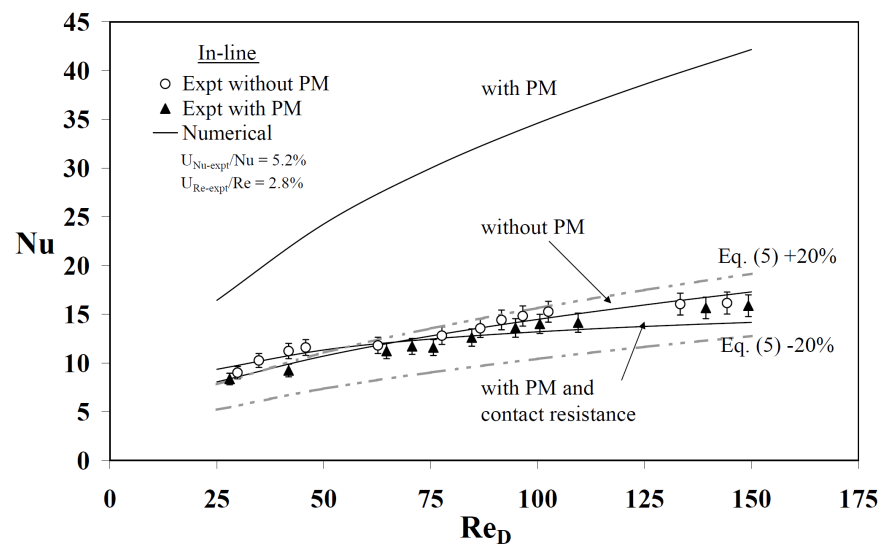

Fig. 4 Average Nusselt number for different Reynolds numbers for inline arrangement

The heat transfer results of inline tube bank without porous medium inter-connectors compared well with the empirical results of inline tube bank. The Nusselt number shows an increasing trend along with increase in Reynolds number as expected. However, there is no significant enhancement in heat transfer for the case with porous medium inter-connectors over the case without the interconnectors. The poor enhancement of heat transfer may be attributed to poor thermal contact between the tubes and porous interconnectors. TŠJoen et al. (2010) reported in an earlier experimental study that the bonding between the porous layer and the pipe is very crucial. Conductive epoxy glue was used in their experiments to join the metal foam on pipe and the results were not encouraging suggesting the need to develop a cost effective and efficient brazing technology for this purpose. In the present work, although brazing was employed, the effect of contact resistance is found to be significant.

To understand the poor performance, the inline tube bank configuration shown in Fig. 1a is considered for numerical simulation, initially without contact resistance between tubes and porous interconnectors and later by introducing thermal contact resistance. A commercially available CFD software is used for the simulations The numerical procedure followed here is similar to that detailed in Raju and Narasimhan (2007).

Numerically predicted heat transfer of inline configuration with porous medium inter-connectors shows a significant three-fold increase in heat transfer and is shown in Figure 4as a thin line tagged as "with PM". This particular case is with no thermal contact resistance. In experimental results this enhancement is not seen due to the presence of contact resistance between the tube surface and the porous medium inter-connectors. The method employed to join the tube surface and inter-connectors is simple brazing which forms a layer of $2 \mathrm{~mm}$ at the joining surface that has considerable thermal resistance. Taking this assumption into consideration the configuration was simulated again by introducing an equivalent contact resistance at the joining surface. Various contact conductivity values from effective thermal conductivity $\left(\mathrm{k}_{e f f}\right)$ of porous medium $\left(\mathrm{k}_{s}\right)$ and fluid $\left(\mathrm{k}_{f}\right)$ were invoked to simulate the heat transfer behaviour for the range of flow considered. The maximum contact conductivity $k_{e f f}=(1-\phi) k_{s}+\phi k_{f}$ and minimum contact conductivity were taken as that of the fluid $\left(\mathrm{k}_{f}\right)$ present in the domain forming a $2 \mathrm{~mm}$ layer between the tube surface and porous medium inter-connectors. These heat transfer results with contact resistance agree with the experimental values.

Hydrodynamic results plotted in Figure 5 for staggered arrangement show that the pressure drop increased with an increase in
Reynolds number for both cases (with and without tube-to-tube porous medium inter-connectors). A 3.5 fold increase in the pressure drop for the case with porous medium is observed, compared to its base line case in the range of flow studied.

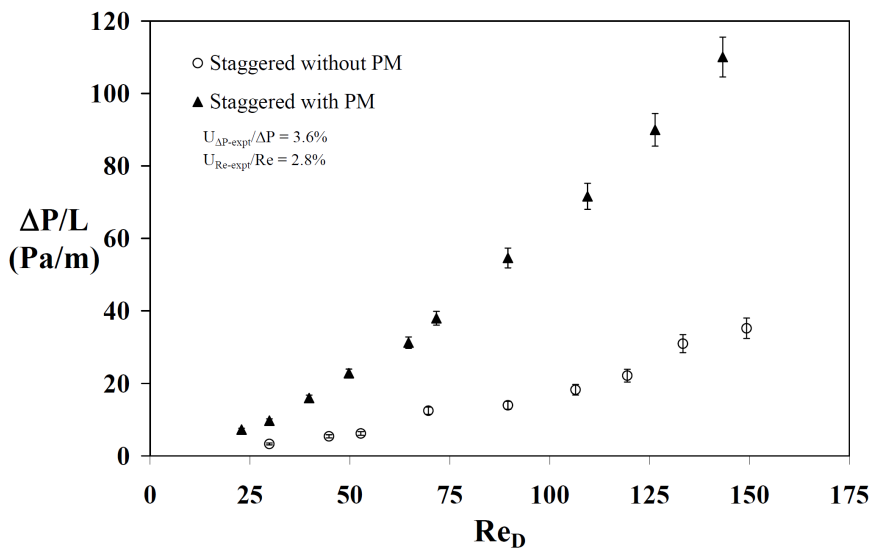

Fig. 5 Longitudinal pressure drop for different Reynolds number for staggered arrangement

Figure 6 shows the average Nusselt number behaviour of the staggered arrangement with and without tube-to-tube porous medium inter-connectors. The Nusselt number shows an increasing trend along with increase in Reynolds number as expected, but comparing with the clear fluid case there is $50 \%$ increase in heat transfer for the case with porous medium inter-connectors.

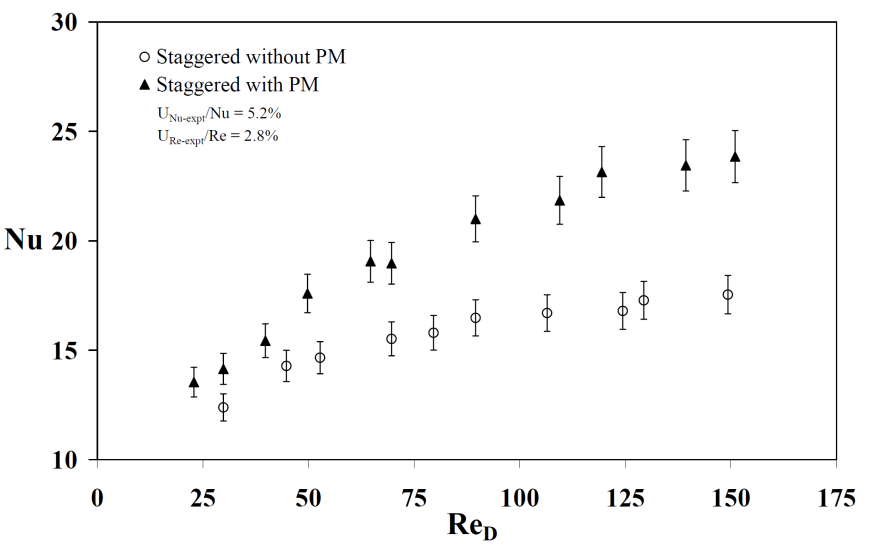

Fig. 6 Average Nusselt number for different Reynolds number for staggered arrangement

Figure 7 explains the overall enhancement ratio of the inline and staggered tube banks with the presence of porous medium. The effect of tube-to-tube porous medium inter-connectors on heat transfer enhancement and change in pressure drop penalty for inline and staggered arrangements is compared by using overall energy gain $(\mathrm{R})$ of the system as

$$
R=\frac{Q_{f}}{U A_{c} \Delta P}
$$

where, $\mathrm{Q}_{f}$ is the heat carried away by the fluid $\mathrm{Q}_{f}=\dot{m} c_{p}$ $\left(\bar{T}_{\text {avg }_{e} x i t}-T_{i n}\right), \mathrm{U}$ is the average velocity through the channel, $\mathrm{A}_{c}$ is 
the area of the cross section and $\Delta P$ is the pressure drop across the tube bank. The overall enhancement ratio (ER) of the tube bank can now be defined using the overall energy gain of the tube bank with and without Porous medium configurations

$$
E R=\frac{R_{\text {withPM }}}{R_{\text {withoutPM }}}
$$

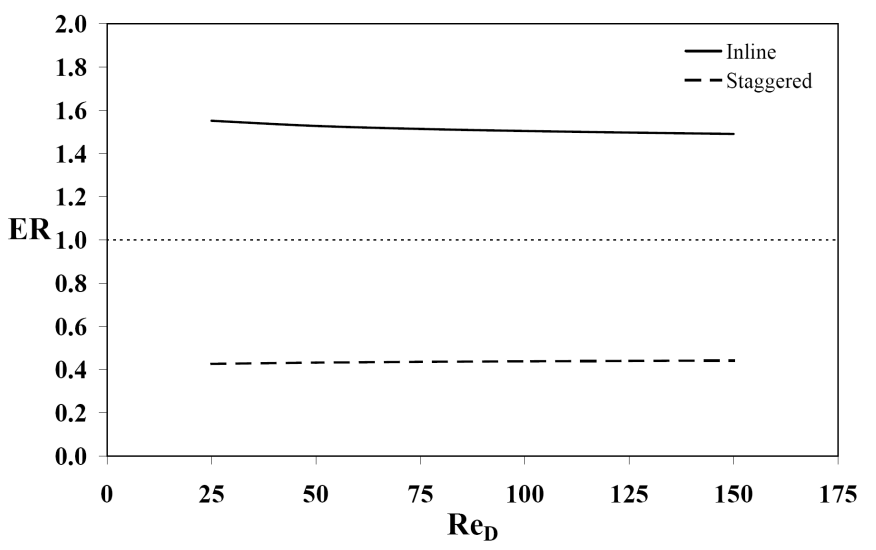

Fig. 7 Enhancement Ratio with porous medium inter-connectors for inline and staggered arrangements

The overall enhancement ratio of the inline arrangement with porous medium is 1.5 times higher than its counterpart. But staggered arrangement shows poor overall performance even though the heat transfer increases considerably, the incurred pressure drop penalty suppresses its merit as a better heat transfer candidate. Nevertheless it can be employed wherever high heat dissipation rates are required with no pump power restrictions.

\section{CONCLUSIONS}

This experimental study investigates the effect of tube-to-tube copper porous inter-connectors on the thermo-hydraulic performance of inline and staggered confined tube banks. The tubes are subjected to a constant and uniform heat flux and are cooled by forced convection under laminar flow range $\left(0<\operatorname{Re}_{D}<150\right)$ using water as cooling fluid.

The presence of the porous medium inter-connector reduces the pressure drop for the inline case. The recirculation and vortices in the tube gaps that contribute to an additional pressure drop are curtailed by the presence of the PM inter-connectors resulting in this pressure drop gain for the inline arrangement with the PM inter-connectors. However, in the staggered arrangement the presence of the porous medium inter-connector uniformly increases the pressure drop by about 3.5 times when compared to the corresponding plain staggered arrangement.

The overall enhancement ratio of the inline arrangement with porous medium is 1.5 times higher than its base-line case. But staggered arrangement shows poor overall performance even though the heat transfer increases considerably; the incurred pressure drop penalty suppresses its merit as a better heat transfer candidate.

\section{NOMENCLATURE}

A surface area of the tube, $\mathrm{m}^{2}$

$A_{c} \quad$ cross-sectional area of the duct, $\mathrm{m}^{2}$

$c_{P} \quad$ specific heat, $\mathrm{J} / \mathrm{kg}-\mathrm{K}$

C form coefficient, $\mathrm{m}^{-1}$

$D \quad$ diameter of the tube, $m$

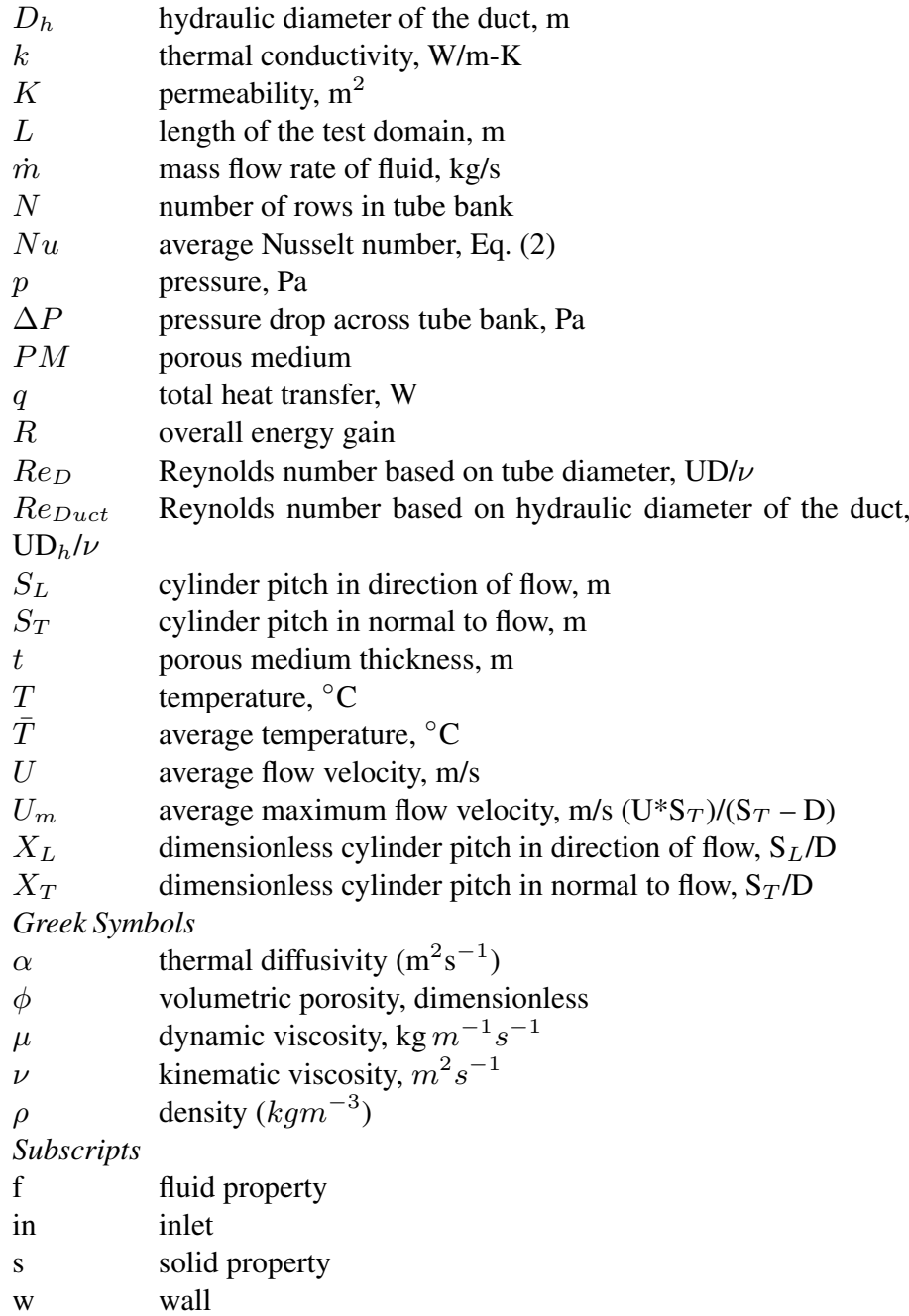

\section{REFERENCES}

Bogdan, I.P., and Mohamad, A.A., 2004a, "An Experimental and Numerical Study on Heat Transfer Enhancement for Gas Heat Exchanger Fitted with Porous Media," International Journal of Heat and Mass Transfer, 47, 4939-4952.

http://dx.doi.org/10.1016/j.ijheatmasstransfer.2004.06.014

Bogdan, I.P., and Mohamad, A.A., 2004b, "Experimental Investigation of the potential of Metallic porous inserts in enhancing Forced convective Heat Transfer," ASME Journal of Heat Transfer, 126, 540-545. http://dx.doi.org/10.1115/1.1773586

Holman, J.P., 2001, Experimental Methods for Engineers, Mc Graw Hill Publishers, New York.

Huang, Z.F., Nakayama, A., Yang, K., Yang, C., and Liu, W., 2010, "Enhancing heat transfer in the core flow by using porous medium insert in a tube," International Journal of Heat and Mass Transfer, 53, 1164 1174 .

http://dx.doi.org/10.1016/j.ijheatmasstransfer.2009.10.038

Jamin, Y.L., and Mohamad, A.A., 2007, "Enhanced heat transfer using porous carbon foam in cross flow - Part I: Forced Convection," ASME Journal of Heat Transfer, 129, 735-742. http://dx.doi.org/10.1115/1.2717240

Lage, J.L., and Narasimhan, A., 2000, Handbook of Porous Media, chap. Porous media enhanced forced convection fundamentals and applications, 357-394, Marcel Dekker, Inc. 
Lauriat, G., and Ghafir, R., 2000, Handbook of Porous Media, chap. Forced convective heat transfer in porous materials, 201-267, Marcel Dekker, New York.

Layeghi, M., 2008, "Numerical analysis of wooden porous media effects on heat transfer from a staggered tube bundle," ASME Journal of Heat Transfer, 130, 014501.

http://dx.doi.org/10.1115/1.2780184

Raju, K.S., and Narasimhan, A., 2007, "Porous Medium Interconnector Effects on the Thermohydraulics of Near-Compact Heat Exchangers Treated as Porous Media," ASME Journal of Heat Transfer, 129, 273281.

http://dx.doi.org/10.1115/1.2427074

Ramana, P.V., Narasimhan, A., and Chatterjee, D., 2010, "Experimental Investigation of the Effect of Tube-to-Tube Porous Medium Interconnectors on the Thermo-hydraulics of Confined Tube Banks," Heat Transfer Engineering, 31:6, 518-526.

http://dx.doi.org/10.1080/01457630903412161

Seyf, H.R., and Layeghi, M., 2010, "Numerical Analysis of Convective Heat Transfer from an Elliptic Pin Fin Heat Sink with and without Metal
Foam Insert," ASME Journal of Heat Transfer, 132, 071401. http://dx.doi.org/10.1115/1.4000951

Straatman, A.G., Gallego, N.C., Thompson, B.E., and Hangan, H., 2006, "Thermal characterization of porous carbon foam - convection in parallel flow," International Journal of Heat and Mass Transfer, 49, 1991-1998. http://dx.doi.org/10.1016/j.ijheatmasstransfer.2005.11.028

TŠJoen, C., de Jaeger, P., Huisseune, H., Van Herzeele, S., Vorst, N., and De Paepe, M., 2010, "Thermo-hydraulic study of a single row heat exchanger consisting of metal foam covered round tubes," International Journal of Heat and Mass Transfer, 53, 3262-3274. http://dx.doi.org/10.1016/j.ijheatmasstransfer.2010.02.055

Yu, Q., Straatman, A.G., and Thompson, B.E., 2006, "Carbonfoam finned tubes in airÜwater heat exchangers," Appied Thermal Engineeringg, 26, 131-143.

http://dx.doi.org/10.1016/j.applthermaleng.2005.06.004

Zukauskas, A., 1987, Advances in Heat Transfer, Vol. 18, chap. Heat Transfer from Tubes in Crossflow, Academic, New York. 